\title{
Application of Artificial Intelligence in the Cultivation of Art Design Professionals
}

\author{
https://doi.org/10.3991/ijet.v16i08.22131 \\ Yan Sun \\ Jiamusi University, Jiamusi, China \\ msxysunyane163. com
}

\begin{abstract}
This paper summarized the problems in the application of artificial intelligence (AI) in the cultivation of art design professionals, and evaluated the promotive effect of $\mathrm{AI}$ in terms of teaching contents, methods, and means. On this basis, an improved fuzzy evaluation system was established to reveal how $\mathrm{AI}$ application enhance the training of art design professionals. Drawing on fuzzy theory, a fuzzy similarity calculation model was developed for fuzzy evaluation. Next, several strategies were proposed for applying AI in the cultivation of art design professionals. This research effectively demonstrated the promotive effect of $\mathrm{AI}$ in the training of art design professionals, and pointed out the ways to improve the training effect.
\end{abstract}

Keywords - Art design, talent cultivation, artificial intelligence (AI), fuzzy theory, evaluation model

\section{Introduction}

In modern education, greater importance is given to the training of professional talents. As an indispensable part of modern education, the art design discipline is playing an important supportive role in the cultivation of art design professionals [1-4]. With the rapid development of modern education technology, especially the extensive application of intelligent education technology, the talent training modes of modern education and modern art design education have also undergone great changes [5-8].

It's well known that AI is widely used in many fields and has achieved good application effect, these applications also provide a good reference for the modern art design education [9-10]. In terms of the application effect of AI in modern art design education, field scholars have proposed ideas and suggestions from various perspectives, which provide good references for improving the application effect of AI in modern education and modern art design education [11-14]. For example, Ding et al. [15] discussed the application of virtual reality (VR) in the cultivation of higher vocational professionals for digital arts. Wu [16] analyzed the training mode of digital media art professionals in the context of Internet. Liang [17] took an art design school in a science and technology college as the research object, and discussed the talent training mode of two-direction visual communication design major from the aspects of curriculum 
reorganization, innovative teaching content, and cloud teaching. Wu [18] discussed the training of digital media art professionals in the process of media integration.

Due to the continuous development of AI technology and the dynamic characteristics of the talent training plans of art design education, the application of $\mathrm{AI}$ in the training of art design professionals is often affected by a few factors, therefore, there are still much room for further research in terms of how to establish new evaluation systems or models to measure and analyze the application effect of AI in the training of art design professionals, as well as the corresponding implementation strategies. The research content in this paper includes five parts: the first part gives an overview of existing studies concerning the application of AI in modern education and modern art design education; the second part analyzes the promotive effect of AI application on the training of art design professionals; the third part establishes an evaluation system and an evaluation model to measure the AI application effect, and realizes fuzzy evaluation of such effect; the fourth part proposes a few strategies for the application of AI the training of art design professionals; the fifth part gives the conclusions.

\section{Promotive Effect of AI Application on the Training of Art Design Professionals}

\subsection{AI application enriches the teaching content of art design education}

In the training of art design professionals, the application of AI not only enriches the teaching content, but also makes the teaching resources more diversified; especially for art design forms that are very special, professional, scarce, obscure, or incomplete, with the help of AI, the relevant art design information could be collected more easily. The advancement and upgrading of computer technology, network information technology, data mining technology and AI technology have brought great help for the collection, summarization, arrangement and sharing of the teaching knowledge and content of art design education, and they have important promotive effect on the teaching content organization of art design courses, the planning of teaching schemes, the formulation of syllabus, the compilation of teaching materials, the instruction of art work creation, and the marketing of art design works, etc. For example, the arts and crafts of the Hezhe nationality (a minority nationality in China) have unique and distinct regional characteristics, however, with the passing of time, the traditional arts and crafts of the Hezhe nationality is facing a crisis that it may be disappear in the future. With the help of AI, we can effectively collect the information of the traditional arts and crafts of Hezhe, and systematically analyze, classify and display their content; on the one hand, traditional arts and crafts of Hezhe can be introduced to the teaching content of art design courses, so that the art forms of minority nationalities can be passed on through classroom teaching content, and art design students could appreciate and have a deeper understanding of the connotation of the traditional arts and crafts of Hezhe; on the other hand, by investigating the online and offline sales of the works of Hezhe arts and crafts and mining the big data, we can establish the market preference styles of Hezhe arts and crafts, and then build database of the types, styles, colors and other characteristics 
of Hezhe arts and crafts, thereby providing references for the creation of Hezhe arts and crafts works.

\subsection{AI application vivifies the teaching methods of art design education}

The teaching methods of art design education include many forms such as teacher explanation and lecturing, discussion, demonstration and presentation, visiting, exercising and practicing, and internship, etc., and the organization forms of the teaching activities are diversified as well. In the implementation process of art design teaching activities, the lecturing teaching method and the discussion teaching method mostly use verbal languages to impart the art design knowledge in an indirect way; the demonstration teaching method and the visiting teaching method mostly use direct contact and perception forms to enable students to obtain the art knowledge in a more direct way; and the practicing and internship teaching methods mostly adopt real training programs to push students to master the art knowledge and skills. Based on the actual application situations of these teaching methods, we can see that, with the application of AI, art design teaching methods have gradually gotten rid of the traditional thinking patterns, for example, the application of multimedia technology enriches the teaching forms of using language to impart art knowledge, and it makes the teaching methods closer to the daily language habits of students. VR and 3D printing can make the perceptionform art design teaching methods have a more real feeling, which can enhance the students' learning experience and it is conductive to their knowledge absorption. Moreover, the comprehensive application of networking information technology, computer technology, VR, and other technologies also provide convenience for the practice-form teaching methods, and it enhances the learning practice and expands the theory learning of art students. Still, with the arts and crafts of Hezhe as the example, network information technology could help to promote the Hezhe arts and crafts online, collect the information of Hezhe arts and crafts from the internet, evaluate the collected materials scientifically, select materials that are suitable for art design teaching, and apply them to the teaching activities of art design education. Also, online digital technology can help to promote the works of Hezhe arts and crafts on the internet, then compare and evaluate the online promotion effect, and select more reliable and effective ways to promote the Hezhe arts and crafts online, thereby forming a cultural atmosphere of Hezhe arts and crafts, which is even better for enhancing the influence and promoting the culture of Hezhe nationality.

\subsection{AI application advances the teaching tools of art design education}

The teaching tools for the training of art design professionals refer to the media, equipment and tools used by art design teachers and students during the conveying of teaching information. With the continuous development of modern technologies and their application in modern education, the teaching tools of art design education have undergone great changes. The traditional teaching tools, such as textbooks and blackboards have gradually changed to various electronic devices and multimedia equipment. During the transformation process, many intelligent equipment has been applied 
to the education of modern art design, making the teaching tools more and more intelligent and advanced. Nowadays, with the fast development of network technology and popularization of its applications, intelligent equipment is playing a very important role in the training of modern art design professionals. Multimedia is the most widely used teaching tool in modern art design education. It could provide illustrated teaching content and rich teaching resources for modern art design education. In addition, a variety of online teaching tools have emerged in recent years, famous ones include online classrooms, flipped classrooms, MOOCs, cloud classrooms, and rain classrooms, and all of these can well promote the teaching activities of art design education and the imparting of teaching content, as well as improve the teaching quality and efficiency. At the same time, one thing should be noted is that, each single teaching tool would have its limitations; and for the art design education which requires to pay attention to both the theoretical knowledge and practical skills, various intelligent teaching tools should be comprehensively integrated for the training of art design professionals. In particular, when it comes to the teaching of minority nationality art design and the promotion of art works, it's necessary to pay more attention to the comprehensive application of AI technology. For example, when teaching the Hezhe arts and crafts and promoting the art creation works of Hezhe culture, on the one hand, various intelligent equipment and modern science and technology should be comprehensively integrated to display the professional knowledge, cultural connotations, creation difficulties, and creation background of the works of arts and crafts of Hezhe, so as to make people have a deeper understanding of the Hezhe culture; on the other hand, database and online platforms of Hezhe arts and crafts could be established, also, in the context of nation-wide internet initiation promoted in China, the database of Hezhe arts and crafts could be further innovated and deepened, so that the existing Hezhe arts and crafts database established by individual creators could be expanded into large Hezhe arts and crafts database that is jointly created by all people. In this way, we can explore and protect the traditional Hezhe arts and crafts works, and then fully mobilize the enthusiasm of Hezhe arts and crafts lovers, thereby enhancing the teaching effect of art design education of Hezhe arts and crafts and improving the art creation abilities of the designers.

In art design education, besides enriching teaching content, vivifying teaching methods and advancing teaching tools, AI application can also improve the teaching efficiency and teaching adaptability of the training of art design professionals. As we all know, AI development and its application in art design education have very important promotive and supportive effect on the training of art design professionals, however, we should also notice that there are still shortcomings in it. For instance, the low intelligent level of AI application, AI application is not systematic, the limited investment in AI application, the insufficient inheritance of AI application, and the superficial concept of AI application, and all these problems require art design teachers to improve them gradually in subsequent teaching works. 


\section{Fuzzy Evaluation of the Promotive Effect of AI on the Training of Art Design Professionals}

To better apply AI in art design education so that it could better promote the teaching quality of art design major and provide better support for the training of art design professionals, it's necessary to effectively measure the promotive effect of AI on the training of art design professionals, for this reason, the corresponding evaluation system and model are required.

\subsection{Problems with the selection of fuzzy indicators}

The evaluation process of the promotive effect of AI on the training of art design professionals often involves multiple aspects, multi-level influencing factors, and the processing of fuzzy information, therefore, it is necessary to reasonably select the evaluation indicators, and this paper holds that the selection of evaluation indicators should follow the scientific, reasonable, logic, objective, purposeful, and transformable principles. The selected indicators should have clear scientific meanings and reasonable logic relationships, they should be consistent with the objective conditions of the training of art design professionals, moreover, these indicators should be representative rather than comprehensive, and are easy to be quantified.

\subsection{Establishment of the evaluation indicator system}

Based on above-mentioned indicator selection principles, this paper proposed an improve evaluation indicator system of the promotive effect of AI on the training of art design professionals, as shown in Table 1. 
Table 1. Evaluation indicator system

\begin{tabular}{|c|c|c|}
\hline System layer & $\begin{array}{c}\text { First-level } \\
\text { indicator }\end{array}$ & Second-level indicator \\
\hline \multirow{30}{*}{$\begin{array}{l}\text { Evaluation indicator system } \\
\text { of the promotive effect of AI } \\
\text { on the training of art design } \\
\text { professionals }\end{array}$} & \multirow{6}{*}{$\begin{array}{l}\text { Teaching } \\
\text { content }\end{array}$} & Richness degree of teaching content \\
\hline & & Whether key and difficult knowledge points are highlighted \\
\hline & & Systematic demonstration of teaching content \\
\hline & & Comprehensiveness of teaching content \\
\hline & & Completion degree of teaching tasks \\
\hline & & Completion degree of teaching goals \\
\hline & \multirow{4}{*}{ Teaching tool } & How well can the teaching tool support the teaching content \\
\hline & & Application of advanced education technologies \\
\hline & & Configuration of intelligent equipment \\
\hline & & Integration with teaching organization forms \\
\hline & \multirow{5}{*}{$\begin{array}{l}\text { Teaching } \\
\text { method }\end{array}$} & Flexible implementation \\
\hline & & Improvement of teaching concept \\
\hline & & Improvement of teaching reform ability \\
\hline & & Improvement of teaching efficiency \\
\hline & & Adaptability of course teaching \\
\hline & \multirow{13}{*}{ Achievement } & Improvement of students' learning interest \\
\hline & & Improvement of students' learning initiative \\
\hline & & Learning participation degree \\
\hline & & Knowledge point adsorption ability \\
\hline & & Knowledge point comprehension and cognition degree \\
\hline & & Student elimination rate \\
\hline & & Unqualified rate of trained talents \\
\hline & & Excellent rate of trained talents \\
\hline & & Talent training satisfaction degree \\
\hline & & Improvement of autonomous learning ability \\
\hline & & Improvement of creative thinking ability \\
\hline & & Improvement of classroom learning atmosphere \\
\hline & & Expansion of learning vision \\
\hline & & Completion degree of learning goals \\
\hline & & Completion degree of learning tasks \\
\hline
\end{tabular}

\subsection{Processing of fuzzy indicator values}

After the evaluation indicator system was established, initial data of different evaluation objects were obtained. Since the evaluation indicators had both qualitative and quantitative types, the data of some indicators may not be that accurate, namely, there might be fuzzy indicators. For this reason, triangular fuzzy numbers were introduced [19-22] to obtain the initial data of indicators of each evaluation object.

In terms of the evaluation of the promotive effect of AI on the training of art design professionals, the initial data $V_{i j}(O)$ of the $i$-th evaluation object with respect to the $j$-th evaluation indicator is:

$$
V_{i j}(O)=\left(v_{i j}^{\min }(O), v_{i j}^{\operatorname{mid}}(O), v_{i j}^{\max }(O)\right)
$$


where, $1 \leq i \leq m, m$ represents the number of fuzzy evaluation objects; $1 \leq j \leq n, n$ represents number of fuzzy evaluation indicators; $v_{i j}^{\min }(O) \leq v_{i j}^{\operatorname{mid}}(O) \leq v_{i j}^{\max }(O)$, $v_{i j}^{\text {min }}(O)$ represents the lower limit of initial data $V_{i j}(O), v_{i j}^{\text {mid }}(O)$ represents the midvalue of the initial data $V_{i j}(O), v_{i j}^{\max }(O)$ represents the upper limit of initial data $V_{i j}(O)$.

At the same time, according to the data model of the initial data $V_{i j}(O)$ established above, $\left|v_{i j}^{\max }(O)-v_{i j}^{\min }(O)\right|$ describes the fuzzy range of $V_{i j}(O)$, and the greater the value range, the higher the uncertainty degree.

For initial data $V_{i j}(O)$ which has the typical triangular fuzzy number structure, its fuzzy membership function $f_{V_{i j}(O)}(v)$ can be expressed as:

$$
f_{v_{i j}(O)}(v)=\left\{\begin{array}{lc}
\frac{v-v_{i j}^{\text {min }}(O)}{v_{i j}^{\text {mid }}(O)-v_{i j}^{\text {min }}(O)} & v_{i j}^{\text {min }}(O) \leq v \leq v_{i j}^{\text {mid }}(O) \\
0 & v \notin\left[v_{i j}^{\text {min }}(O), v_{i j}^{\text {max }}(O)\right] \\
\frac{v_{i j}^{\max }(O)-v}{v_{i j}^{\text {max }}(O)-v_{i j}^{\text {mid }}(O)} & v_{i j}^{\text {mid }}(O) \leq v \leq v_{i j}^{\text {max }}(O) \\
1 & v=v_{i j}^{\text {mid }}(O)
\end{array}\right.
$$

The diagram of the corresponding fuzzy membership function is shown in Figure 1.

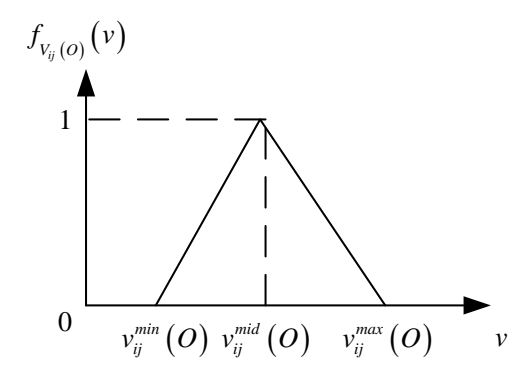

Fig. 1. Fuzzy membership function of typical triangular fuzzy number $V_{i j}(O)$

If there is $v_{i j}^{\min }(O)=v_{i j}^{\text {mid }}(O) \leq v_{i j}^{\max }(O)$, then $f_{V_{i j}(O)}(v)$ is the lower-limit fuzzy membership function of the initial data $V_{i j}(O)$, that is:

$$
f_{v_{i j}(O)}(v)=\left\{\begin{array}{lr}
1 & v \leq v_{i j}^{\text {min }}(O) \\
\frac{v_{i j}^{\max }(O)-v}{v_{i j}^{\max }(O)-v_{i j}^{\text {mid }}(O)} & v_{i j}^{\text {mid }}(O) \leq v \leq v_{i j}^{\text {max }}(O) \\
0 & v \geq v_{i j}^{\max }(O)
\end{array}\right.
$$

The diagram of the corresponding fuzzy membership function is shown in Figure 2. 


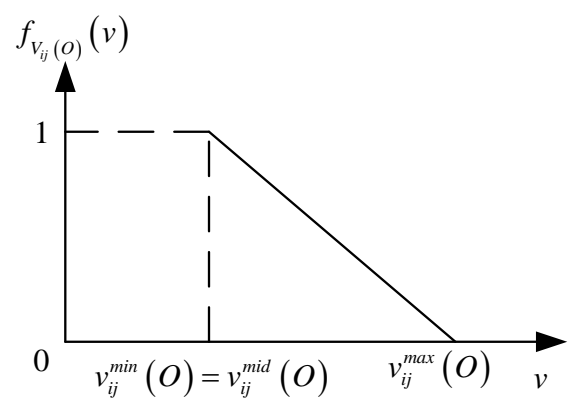

Fig. 2. Lower-limit fuzzy membership function of initial data $V_{i j}(O)$

If there is $v_{i j}^{\min }(O) \leq v_{i j}^{\operatorname{mid}}(O)=v_{i j}^{\max }(O)$, then $f_{V_{i j}(O)}(v)$ is the upper-limit fuzzy membership function of the initial data $V_{i j}(O)$, that is:

$$
f_{v_{i j}(O)}(v)=\left\{\begin{array}{lc}
1 & v \geq v_{i j}^{\text {max }}(O) \\
\frac{v-v_{i j}^{\text {min }}(O)}{v_{i j}^{\text {mid }}(O)-v_{i j}^{\text {min }}(O)} & v_{i j}^{\text {min }}(O) \leq v \leq v_{i j}^{\text {mid }}(O) \\
0 & v \leq v_{i j}^{\text {min }}(O)
\end{array}\right.
$$

The diagram of the corresponding fuzzy membership function is shown in Figure 3.

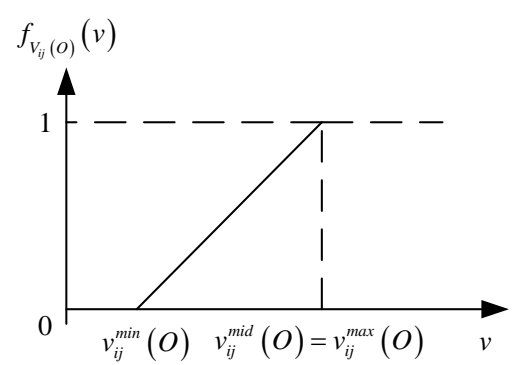

Fig. 3. Upper-limit fuzzy membership function of initial data $V_{i j}(O)$

Thus, based on the initial data obtained above, an initial data matrix $\mathbf{V}$ can be constructed as:

$$
\mathbf{V}=\left[\begin{array}{ccccc}
V_{11}(O) & \cdots & V_{1 j}(O) & \cdots & V_{1 n}(O) \\
\vdots & \vdots & \vdots & \vdots & \vdots \\
V_{i 1}(O) & \cdots & V_{i j}(O) & \cdots & V_{i n}(O) \\
\vdots & \vdots & \vdots & \vdots & \vdots \\
V_{m 1}(O) & \cdots & V_{m j}(O) & \cdots & V_{m n}(O)
\end{array}\right]
$$

In terms of the types of the fuzzy evaluation indicators, some are benefit-type indicators, while some are cost-type indicators. 
For a benefit-type indicator $j$, its normalized triangular fuzzy value $U_{i j}(O)$ is:

$$
\begin{aligned}
& U_{i j}(O)=\left(u_{i j}^{\min }(O), u_{i j}^{\operatorname{mid}}(O), u_{i j}^{\max }(O)\right)= \\
& \frac{1}{\max _{1 \leq i \leq m}\left(v_{i j}^{\max }(O)\right)} *\left(v_{i j}^{\min }(O), v_{i j}^{\operatorname{mid}}(O), v_{i j}^{\max }(O)\right)
\end{aligned}
$$

where, $u_{i j}^{\min }(O) \leq u_{i j}^{\operatorname{mid}}(O) \leq u_{i j}^{\max }(O)$.

For a cost-type indicator $\mathrm{j}$, its normalized triangular fuzzy value $\mathrm{U}_{\mathrm{ij}}(\mathrm{O})$ is:

$$
\begin{aligned}
& U_{i j}(O)=\left(u_{i j}^{\min }(O), u_{i j}^{\text {mid }}(O), u_{i j}^{\max }(O)\right)= \\
& \min _{1 \leq i \leq m}\left(v_{i j}^{\min }(O)\right) *\left(\frac{1}{v_{i j}^{\max }(O)}, \frac{1}{v_{i j}^{\operatorname{mid}}(O)}, \frac{1}{v_{i j}^{\min }(O)}\right)
\end{aligned}
$$

Then, the normalized data matrix $\mathbf{U}$ is:

$$
\mathbf{U}=\left[\begin{array}{ccccc}
U_{11}(O) & \cdots & U_{1 j}(O) & \cdots & U_{1 n}(O) \\
\vdots & \vdots & \vdots & \vdots & \vdots \\
U_{i 1}(O) & \cdots & U_{i j}(O) & \cdots & U_{i n}(O) \\
\vdots & \vdots & \vdots & \vdots & \vdots \\
U_{m 1}(O) & \cdots & U_{m j}(O) & \cdots & U_{m n}(O)
\end{array}\right]
$$

\subsection{Weights of fuzzy indicators}

Based on the constructed fuzzy evaluation indicator system, since different evaluation indicators have different degrees of importance to the evaluation results, they should be assigned with different weight values. The Analytic Hierarchy Process (AHP) [23-26] is an effective method of indicator weight assignment due to its merits of simple calculation, reliable results, and easy application, therefore, this paper employed it to assign weight values to the evaluation indicators.

After the valuation indicator system was constructed, field experts were invited to compare the indicators in pairs and give scores, then an initial indicator weight matrix $\mathbf{R}$ was established as:

$$
\mathbf{R}=\left[\begin{array}{ccccc}
r_{11}(G) & \cdots & r_{1 j}(G) & \cdots & r_{1 n}(G) \\
\vdots & \vdots & \vdots & \vdots & \vdots \\
r_{i 1}(G) & \cdots & r_{i j}(G) & \cdots & r_{i n}(G) \\
\vdots & \vdots & \vdots & \vdots & \vdots \\
r_{n 1}(G) & \cdots & r_{n j}(G) & \cdots & r_{n n}(G)
\end{array}\right]
$$

where, $r_{i j}(G)$ represents the degree of importance of evaluation indicator $i$ with respect to evaluation indicator $j$, generally its value adopts a ratio scale of $1-9$, and it satisfies $r_{i j}(G)=\frac{1}{r_{j i}(G)}$.

Then, the indicator weight matrix $\mathbf{R}$ was normalized, that is, there is: 


$$
H_{j}(G)=\sum_{i=1}^{n}\left(r_{i j}(G) / \sum_{i=1}^{n} r_{i j}(G)\right)
$$

The largest eigenvalue $\lambda(\boldsymbol{R})_{\max }$ of the obtained indicator weight matrix $\mathbf{R}$ is:

$$
\lambda_{\max }(\mathbf{R})=\sum_{j=1}^{n} \frac{(\mathbf{R} * W)_{i}}{n W_{i}}
$$

Then $\mathbf{R}$ was subject to consistency check:

$$
C R=\left(\frac{\lambda_{\max }(\mathbf{R})-n}{n-1}\right) / R I
$$

where, $R I$ represents the random index, its value can be selected from the corresponding table.

If there is $C R<0.1$, it indicates that $\mathbf{R}$ meets the consistency check requirement, and the weight $w_{j}$ of the corresponding evaluation indicator $j$ is:

$$
w_{j}=H_{j}(G) / \sum_{j=1}^{n} H_{j}(G)
$$

If there is $C R>0.1$, it indicates that $\mathbf{R}$ does not meet the consistency check requirement, and its weight value needs to be assigned again.

\subsection{The fuzzy similarity degree calculation model of evaluation indicators}

After above processing, the normalized value of fuzzy evaluation object $i$ with respect to evaluation indicator $j$ can be obtained as $U_{i j}(O)=$ $\left(u_{i j}^{\min }(O), u_{i j}^{\text {mid }}(O), u_{i j}^{\max }(O)\right)$, then the maximum triangular fuzzy number $U_{j}^{\Omega}(O)$ of evaluation indicator $j$ is:

$$
U_{j}^{\Omega}(O)=\left(\max _{1 \leq i \leq m}\left(u_{i j}^{\min }(O)\right), \max _{1 \leq i \leq m}\left(u_{i j}^{\operatorname{mid}}(O)\right), \max _{1 \leq i \leq m}\left(u_{i j}^{\max }(O)\right)\right)
$$

The minimum triangular fuzzy number $U_{j}^{\mho}(O)$ of evaluation indicator $j$ is:

$$
U_{j}^{\square}(O)=\left(\min _{1 \leq i \leq m}\left(u_{i j}^{m i n}(O)\right), \min _{1 \leq i \leq m}\left(u_{i j}^{m i d}(O)\right), \min _{1 \leq i \leq m}\left(u_{i j}^{\text {max }}(O)\right)\right)
$$

Then, the fuzzy similarity $\varphi_{i j}^{\Omega}(O)$ between evaluation object $i$ with respect to evaluation indicator $j$ and the maximum triangular fuzzy number $U_{j}^{\Omega}(O)$ is: 


$$
\begin{aligned}
& \varphi_{i j}^{\Omega}(O)= \\
& u_{i j}^{m i n}(O) * \max _{1 \leq i \leq m}\left(u_{i j}^{\min }(O)\right)+u_{i j}^{m i d}(O) * \max _{1 \leq i \leq m}\left(u_{i j}^{m i d}(O)\right)
\end{aligned}
$$

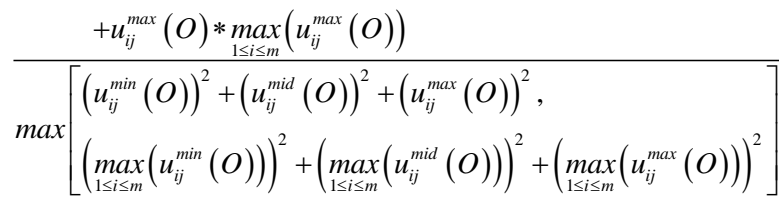

And the fuzzy similarity $\varphi_{i j}^{\mho}(O)$ between evaluation object $i$ with respect to evaluation indicator $j$ and the minimum triangular fuzzy number $U_{j}^{\mho}(O)$ is:

$$
\begin{aligned}
& \varphi_{i j}^{\Omega}(O)= \\
& u_{i j}^{\text {min }}(O) * \min _{1 \leq i \leq m}\left(u_{i j}^{\text {mid }}(O)\right)+u_{i j}^{\text {mid }}(O) * \min _{1 \leq i \leq m}\left(u_{i j}^{\text {mid }}(O)\right)
\end{aligned}
$$

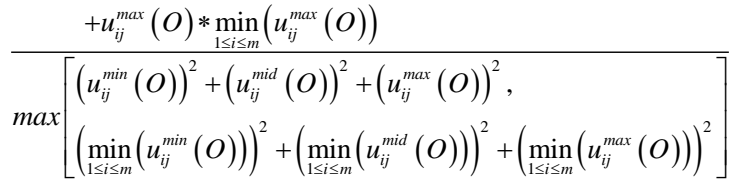

\subsection{Fuzzy evaluation model and its realization}

Through above processing, the weighted comprehensive fuzzy similarity $\psi_{i}^{\Omega}(O)$ between evaluation object $i$ with respect to the fuzzy evaluation indicator set and the maximum triangular fuzzy number $U_{j}^{\Omega}(O)$ is:

$$
\psi_{i}^{\Omega}(O)=\sum_{j=1}^{n}\left(w_{j} * \varphi_{i j}^{\Omega}(O)\right)
$$

And the weighted comprehensive fuzzy similarity $\psi_{i}^{\mho}(0)$ between evaluation object $i$ with respect to the fuzzy evaluation indicator set and the minimum triangular fuzzy number $U_{j}^{\mho}(O)$ is:

$$
\psi_{i}^{\sqcap}(O)=\sum_{j=1}^{n}\left(w_{j} * \varphi_{i j}(O)\right)
$$

Then, the comprehensive similarity $\psi_{i}(O)$ of fuzzy evaluation object $i$ is:

$$
\psi_{i}(O)=\frac{\psi_{i}^{\Omega}(O)}{\psi_{i}^{\Omega}(O)+\psi_{i}^{\square}(O)}
$$

According to the size of the comprehensive similarity $\psi_{i}(O)$, the optimal evaluation object or the evaluation object that meets the evaluation threshold can be obtained. 


\section{Application Strategies of AI in the Training of Art Design Professionals}

\subsection{Use AI to better display and demonstrate the teaching content}

In art design education, an important starting point for applying AI to art teaching is to intuitively, vividly, comprehensively and systematically display the teaching content to the students, so that they can have more real and impressive feelings about the teaching content. Since AI technologies are in constant developing and the technical skills are upgrading, therefore, applying AI in the teaching content demonstration of art design education can make the demonstration methods more diversified. In the AI application process, the objective conditions of art design education should be combined to give the teaching content demonstrations. For example, in case of basic and general knowledge content, we could design digital courseware using network technology, interactive technology, audio and video technology, and computer technology, so that the teaching content demonstration could be more scientific and systematic; in case of technical skills and practical operations, we could consider to use VR to make the teaching content have a more real feeling, so that students could perceive them in a more intuitive way; in case of very professional teaching content, multi-media technology could be used to break the time and space limits for students' art design learning, so that they could better absorb the teaching content of art design education.

\subsection{Use AI to improve and upgrade the teaching tools}

Besides increasing display patterns of teaching content, another role of AI application in art design education is to improve the teaching tools. As we all know, the traditional art design activities are mostly carried out in classrooms, blackboards and chalks are the main teaching tools of art teachers, and such primitive teaching tools have greatly limited the teaching efficiency and effect. With the help of AI, art design teaching tools have gradually become more diversified and intelligent, and they have a good promotive effect on the imparting of teaching knowledge of the art design major. Investigations show that, the promotive effect of AI not only lies in the improvement of teaching tools, but also lies in every link of the teaching activities. For example, in terms of teaching content preparation, with the help of AI, the intelligent content push function enables art design students to rapidly obtain the learning content that is consistent with their learning goals. In terms of classroom learning process, AI applications can strengthen the interactivity of the teaching content, and it can facilitate the construction of a more interactive classroom communication channel. In terms of afterschool learning, AI could be applied to promote the feedback of learning effect and test the performance, it could also help to improve the assessment mechanism, and thereby promoting the effective completion of teaching tasks. In addition, it should also be noted that the teaching tools in each link, such as pre-class preview, classroom learning, and after-class review are not isolated, but combined, mutual-supportive, and mutual- 
assisted. Therefore, when emphasizing the teaching tools of individual teaching link, attention should be paid to the connection of each teaching link.

\subsection{Use AI to improve the professional teaching method}

The actual situations of teaching activities in art design education show that, the implementation of art design teaching activities should serve the training goals of art design professionals, for different training goals, the selected teaching method should vary accordingly. In essence, considering the different times, social backgrounds, and cultures, the selection of teaching methods should not only adapt to the characteristics of the time, but also be in line with the requirements of teaching tasks and teaching goals of current art design education; moreover, teaching method selection should also be consistent with the teaching tools and teaching activities of art design major, and it should be able to reflect the behavioural correlations between teachers and teachers. To use AI to improve the professional teaching method of art design education, the following aspects would require our attention: first, the AI-integrated art design teaching method should be able to reflect the value concept and teaching ideas of current art design education, and realize the teaching goals. Second, the AI-integrated art design teaching tools should be able to form an integrated whole with the teaching content of art design education. Third, the AI-integrated art design teaching tools should be able to combine with the professional teaching organization forms of art design major, and promote the smooth implementation of teaching organization works. Therefore, the application of $\mathrm{AI}$ in art design teaching activities must be adaptive to the teaching methods of art design education, no matter which teaching method is adopted in the teaching activities, such as face-to-face lecturing, Q\&A, argumentation, discussion, demonstration, experiments, practice, visiting, discovery, and inquiry, etc., the proper AI technology should be chosen based on the teaching goals and teaching tasks.

\subsection{Use AI to construct professional teaching platform}

For the influence of AI application on the teaching effect of art design education, one important influencing factor is the construction of teaching platform, the higher the intelligent level of the teaching platform, the more conductive it is to the implementation of art teaching activities, and the better the teaching effect. On the contrary, a low intelligent level teaching platform can hardly help to improve the teaching effect of art design courses. Therefore, obviously, how to construct a good professional art design teaching platform based on AI technologies is of great significance, and construction of the AI-based teaching platform could be divided into two aspects: the hardware facility construction, and the software system construction. Hardware facilities and software systems with good performance, operability, stability, convenience, maintainability and upgradeability should be chosen for the platform construction. Both the hardware configuration and software development require reasonable and effective allocation of manpower, materials and financial resources. Only sufficient basic conditions could provide guarantee for the in-depth application of AI in art design education, and ensure the smooth implementation of intelligent art design teaching activities. 


\subsection{Pay attention to the emotional bonding of $\mathrm{AI}$ and art design teaching}

Art design is inseparable from human emotions. From the perspective of the essential content of art works, the connotation of art design works is an external expression of human emotions, and the expression form of art design works is often influenced by cultural factors, economic factors, and social factors, etc. With the rapid development of AI and its in-depth application in the field of education, it is necessary to use AI to reflect the human emotion factors during the implementation process of art design teaching activities, for example, AI technologies could be employed to express the design ideas of the art works, and make the art works better display its immersive characteristics. AI application in art design teaching activities can deepen the time and space feelings of students' artistic creations, release their creative thoughts to the greatest extent, and expand their art design imagination space. Using AI technology, the professional knowledge of art design could be classified, sorted and processed systematically; combining with the learning characteristics of students, the art design knowledge and creation modes could be classified adaptively to help students build their own emotional world and art design knowledge library with cultural accumulations, in this way, the teaching quality and efficiency of art design education could be improved, within the limited learning time, art design students could obtain more practical experience of art design and store more art design knowledge, and ultimately create more excellent art works. In addition, the emotional bonding of $\mathrm{AI}$ and art design should also pay attention to displaying the teaching results using $\mathrm{AI}$, that is, using $\mathrm{AI}$ to restore classical art design works and artistic achievements and display the emotional expressions of the art works in an all-round way, so that it could better fit students' adaptive learning status; moreover, via AI, we could realize intelligent interaction with art design teaching materials, formulate corresponding teaching content and teaching plans according to the emotional requirements of art design creation of students, so as to improve the experience feelings of art design creation to the greatest extent, and enhance art students' ability to absorb the professional knowledge of art design major. Furthermore, the emotional bonding of $\mathrm{AI}$ and art design should also pay attention to the integration of $\mathrm{AI}$ and modern art design education technologies, that is, to use AI to enhance students' interest and enthusiasm for learning. Through survey and statistical analysis, we can know that the application of VR, 3D printing, human-computer interaction, multimedia technology, and network information technology can effectively enhance students' interest in art design learning, making it easier for them to master the true meaning of art design creation.

\section{Conclusion}

AI technology plays a very important role in the training of art design professionals. First, this paper analysed the promotive effect of AI on the training of art design professionals, then based on a variety of influencing factors, it established an improve fuzzy evaluation indicator system to measure such promotive effect of AI. At the same time, considering the fuzzy feature of some evaluation indicators, this paper employed AHP and triangular fuzzy numbers, and established the corresponding evaluation model 
to calculate the fuzzy similarity degree, thereby realizing the fuzzy evaluation of the promotive effect of AI on the training of art design professionals. At last, this paper proposed a few strategies for the application of AI in the training of art design professionals, which provided a good guidance for improving the application effect of AI in the cultivation of art design professionals.

\section{Acknowledgement}

Fund type: Basic scientific research fund of Education Department of Heilongjiang Province. Project name: Networked and Digitized Inheritance and Development Path of Arts and Crafts of Hezhe Nationality in Heilongjiang Province. Project number: 2018-KYYWF-0977

\section{$7 \quad$ References}

[1] Gao, Y. (2020). Blended Teaching Strategies for Art Design Major ourses in Colleges, International Journal of Emerging Technologies in Learning, 15(24), pp. 145-158. https://doi.org/10.3991/ijet.v15i24.19033

[2] Peng, J. (2020). Intelligent Technology-Based Improvement of Teaching Ability of Professional Courses in Art Design, International Journal of Emerging Technologies in Learning, 15(23), 193-207. https://doi.org/10.3991/ijet.v15i23.19029

[3] Wang, J.J. (2019). Exploration and Construction of Innovative Talents Training Mode Taking the Art Design Major of High Vocational School as an Example. Journal of Tianjin Vocational Institutes, 21(2): 16-20. https://doi.org/10.3969/j.issn.1673-582X.2019.02.004

[4] Winkler-Schwartz, A., Bissonnette, V., Mirchi, N., Ponnudurai, N., Yilmaz, R., Ledwos, N., Del Maestro, R. F. (2019). Artificial intelligence in medical education: best practices using machine learning to assess surgical expertise in virtual reality simulation. Journal of surgical education, 76(6): 1681-1690. https://doi.org/10.1016/j.jsurg.2019.05.015

[5] Chen, D., Li, F. (2020). Talent Cultivation Mode Innovation of Art Design in Vocational Colleges. Journal of Zhejiang Water Conservancy and Hydropower College, 32(4): 89-92. https://doi.org/10.3969/j.issn.2095-7092.2020.04.022

[6] Fei, S.B. (2019). Practical Research on the Training Mode of Modern Apprenticeship Talents in Environmental Art Design Major of Higher Vocational Colleges_-Taking Taizhou Polytechnic College as an Example. Journal of Taizhou Polytechnical College, 19(3): 4-6. https://doi.org/10.3969/j.issn.1671-0142.2019.03.002

[7] Hwang, G.J., Xie, H., Wah, B.W., Gašević, D. (2020). Vision, challenges, roles and research issues of Artificial Intelligence in Education. Computers and Education: Artificial Intelligence, 1: 1-14. https://doi.org/10.1016/j.caeai.2020.100001

[8] Chassignol, M., Khoroshavin, A., Klimova, A., Bilyatdinova, A. (2018). Artificial Intelligence trends in education: a narrative overview. Procedia Computer Science, 136: 1624. https://doi.org/10.1016/i.procs.2018.08.233

[9] Paschen, U., Pitt, C., Kietzmann, J. (2020). Artificial intelligence: Building blocks and an innovation typology. Business Horizons, 63(2): 147-155. https://doi.org/10.1016/j.bushor. $\underline{2019.10 .004}$ 
[10] Somasundaram, M., Junaid, K.M., Mangadu, S. (2020). Artificial intelligence (AI) enabled intelligent quality management system (IQMS) for personalized learning path. Procedia Computer Science, 172: 438-442. https://doi.org/10.1016/j.procs.2020.05.096

[11] Ahmad, M.F., Ghapar, W.R.G.W.A. (2019). The Era of Artificial Intelligence in Malaysian Higher Education: Impact and Challenges in Tangible Mixed-Reality Learning System toward Self Exploration Education (SEE). Procedia Computer Science, 163: 2-10. https:// doi.org/10.1016/j.procs.2019.12.079

[12] Bajaj, R., Sharma, V. (2018). Smart Education with artificial intelligence-based determination of learning styles. Procedia computer science, 132: 834-842. https://doi.org/ 10.1016/j.procs.2018.05.095

[13] Gao, G.Y. (2020). Innovation and Practice of the Training Mode of "One Body, Two Wings and Four Integrations" for Art Design Program in Higher Vocational College:a Case Study of Guangdong Polytechnic of Science and Trade. Journal of Shunde Polytechnic, 18(2): 4752. https://doi.org/10.3969/j.issn.1672-6138.2020.02.011

[14] Li, Y.W. (2020). Thoughts on Innovative and Integrated Training Mode of Art and Design Talents. Design Research, 10(4): 1-5. https://doi.org/10.3963/j.issn.2095-0705.2020.04. $\underline{001}$

[15] Ding, Y.Z., Wang, R.J., Zhang, Y.Q. (2019). The application of virtual reality technology in innovating the talent training mode of digital art major in Higher Vocational Colleges. China CIO News, 2019(5): 170-171. https://doi.org/10.3969/j.issn.1001-2362.2019.05.124

[16] Wu, W.Y. (2019). Analysis on the training mode of digital media art professionals in the Internet Environment. Media Form, 2(12): 34-35. https://doi.org/10.3969/j.issn.20965079.2019.12.016

[17] Liang, G.B. (2020). Talent training mode research of two direction visual communication design major_take Keyi college of Zhejiang Sci-Tech University as an example. Design, 33(21): 73-75.

[18] Wu, X.M. (2019). Research on the cultivation of digital media art talents in the process of media convergence. View on Publishing, 2019(10): 82-84. https://doi.org/10.16491/j.cnki. cn45-1216/g2.2019.10.025

[19] Son, N.T.K. (2018). A foundation on semigroups of operators defined on the set of triangular fuzzy numbers and its application to fuzzy fractional evolution equations. Fuzzy Sets and Systems, 347: 1-28. https://doi.org/10.1016/j.fss.2018.02.003

[20] Chandra, S., Aggarwal, A. (2015). On solving matrix games with pay-offs of triangular fuzzy numbers: Certain observations and generalizations. European Journal of Operational Research, 246(2): 575-581. https://doi.org/10.1016/j.ejor.2015.05.011

[21] Tseng, M.L., Lim, M., Wu, K.J., Zhou, L., Bui, D.T.D. (2018). A novel approach for enhancing green supply chain management using converged interval-valued triangular fuzzy numbers-grey relation analysis. Resources, Conservation and Recycling, 128: 122-133. https://doi.org/10.1016/j.resconrec.2017.01.007

[22] Seresht, N.G., Fayek, A.R. (2019). Computational method for fuzzy arithmetic operations on triangular fuzzy numbers by extension principle. International Journal of Approximate Reasoning, 106: 172-193. https://doi.org/10.1016/j.ijar.2019.01.005

[23] Kilic, B., Ucler, C. (2019). Stress among ab-initio pilots: A model of contributing factors by AHP. Journal of Air Transport Management, 80: 101706. https://doi.org/10.1016/ j.jairtraman.2019.101706

[24] Breaz, R.E., Bologa, O., Racz, S.G., Crenganiş, M. (2019). Selecting between CNC turning centers using a combined AHP and fuzzy approach. Procedia Computer Science, 162: 290297. https://doi.org/10.1016/j.procs.2019.11.287 
[25] Durmuşoğlu, Z.D.U. (2018). Assessment of techno-entrepreneurship projects by using Analytical Hierarchy Process (AHP). Technology in Society, 54: 41-46. https://doi.org/ 10.1016/j.techsoc.2018.02.001

[26] Konstantinos, I., Georgios, T., Garyfalos, A. (2019). A Decision Support System methodology for selecting wind farm installation locations using AHP and TOPSIS: Case study in Eastern Macedonia and Thrace region, Greece. Energy Policy, 132: 232-246. https://doi.org/10.1016/j.enpol.2019.05.020

\section{Author}

Yan Sun is a full-time teacher and lecturer at the Academy of Fine Arts of Jiamusi University, Jiamusi 154007, China, a member of the Chinese Small Minority Nationalities, a member of the Chinese Folk Artists Association, a member of the Heilongjiang Art Design Association, and a member of the Jiamusi Artists Association. msxysunyan@163.com

Article submitted 2021-02-11. Resubmitted 2021-02-24. Final acceptance 2021-02-25. Final version published as submitted by the authors. 